\title{
CONCORDANCIA ENTRE LA PERCEPCIÓN MATERNA DEL PESO Y PESO REAL DE HIJOS ESCOLARES
}

\section{CONCORDANCE BETWEEN MATERNAL PERCEPTION OF WEIGHT AND REAL WEIGHT OF SCHOOL}

CHILDRENS

VEGA-GRIMALDO MIGUEL ÁNGEL*, SANTOS-FLORES JESÚS MELCHOR*, GUEVARA-VALTIER MILTON CARLOS**,

PAZ-MORALES MARÍA DE LOS ÁNGELES**, GUTIÉRREZ-VALVERDE JUANA MERCEDES***.

\section{ABSTRACT}

Introduction: Overweight and obesity are associated to a greater extent for future complications in adulthood and to suffer chronic non-transmissible chronic diseases at an early age, an important factor that contributes to this is the inadequate perception that mothers have regarding their children's weight. Objectives: To classify the maternal perception of their children's weight by words and images in appropriate or inappropriate and the latter in underestimation or overestimation. Methods: Descriptive-transversal study, consisting of 30 dyads (mother-child), sociodemographic data card was applied, survey to assess maternal perception by words/images and anthropometric measures were taken to the children. Information was analyzed through the SPSS statistical package, using descriptive statistics. Results: Greater adequate perception of the mothers was identified with respect of their children weight, by words and images (56.7\% and $53.3 \%$ ). In the inadequate perception, greater underestimation was identified in both perception by words and images (100\% and $78.6 \%)$. Conclusions: There is agreement between the maternal perception of the weight and real weight of the schoolchild since there is a greater adequate perception between both variables. It is necessary to study other tools to raise awareness among mothers whose children have a weight problem.

Key words: Weight perception, overweight, obesity, body weight (DeCS, BIREME).

\section{RESUMEN:}

ntroducción: El sobrepeso y obesidad se asocian en mayor medida a complicaciones futuras en la edad adulta y de padecer enfermedades crónicas no transmisibles a edades tempranas, un importante factor que contribuye a esto es la percepción inadecuada que tienen las madres respecto al peso de sus hijos. Objetivos: Clasificar la percepción materna del peso de sus hijos por palabras e imágenes en adecuada o inadecuada y esta última en subestimación o sobreestimación. Métodos: Estudio descriptivo-transversal, muestra conformada por 30 díadas (madre-hijo), se aplicó cédula de datos sociodemográficos, encuesta para evaluar la percepción materna por palabras/imágenes y se tomaron medidas antropométricas a los hijos. Se analizó información mediante paquete estadístico SPSS, empleando estadística descriptiva. Resultados: Se encontró mayor percepción adecuada en las madres respecto al peso de los hijos, por palabras e imágenes (56.7\% y 53.3\%), en la percepción inadecuada se identificó mayor subestimación tanto en la percepción por palabras como imágenes (100\% y 78.6\%). Conclusiones: Existe concordancia entre la percepción materna del peso y peso real del hijo escolar ya que existe una mayor percepción adecuada entre ambas variables. Es necesario el estudio de otras herramientas para concientizar a las madres que sus hijos presentan un problema de peso.

Palabras Clave: Percepción del peso, sobrepeso, obesidad, peso corporal (DeCS, BIREME).

*Licenciatura en
Enfermería, Facultad de
Enfermería, Universidad
Autónoma de Nuevo
León. E-mail: miguel.
angel.vg@hotmail.com;
miguel.vegagrm@uanl.
edu.mx

*Licenciatura en Eermeria, Facultad de Autónoma de Nuevo León. E-mail: miguel. miguel.vegagrm@uanl. edu.mx
**Doctorado en Educación, Docente Investigador, Facultad de Enfermería, Universidad Autónoma de Nuevo León.
***Doctorado en Ciencias de Enfermería, Docente Investigador, Facultad de Enfermería, Universidad Autónoma de Nuevo León. 


\section{INTRODUCCIÓN}

El Sobrepeso y Obesidad (SP-OB) son una de las problemáticas en salud pública más graves del siglo $X X I$ y se está extendiendo a la población infantil (1). El SP-OB infantil se asocia con una mayor probabilidad de obesidad, muerte prematura y discapacidad en la edad adulta, así como de padecer a edades más tempranas enfermedades crónicas no transmisibles como la diabetes mellitus, hipertensión, enfermedades cardiovasculares, entre otras (2). La prevalencia de SP-OB ha aumentado a un ritmo alarmante, debido a que se calcula que en el 2010 se contaba con 42 millones de niños con SP en todo el mundo, de los que cerca de 35 millones viven en países de desarrollo, como lo es México (2). En nuestro país, de acuerdo al Instituto Nacional de Salud Publica en su Encuesta Nacional de Salud y Nutrición (ENSANUT) en el estado de Nuevo León las prevalencias de SP-OB para niños y niñas en edad escolar (6 a 12 años) fueron de $20.4 \%$ y $19.8 \%$, respectivamente (suma de SP-OB, 40.2\%). La prevalencia de sobrepeso en localidades urbanas disminuyó de 20.3 a $19.9 \%$, pero en el área rural aumentó de $15.9 \%$ a $28.8 \%$ la suma de ambas condiciones de estado de nutrición (sobrepeso más obesidad) fue mayor para los niños (43.9\%) en comparación con las niñas (36.4\%) ${ }^{(3)}$.

Existen distintos factores que contribuyen al SP-OB en la infancia, algunos de ellos son los factores familiares que tienen gran importancia sobre los hábitos alimenticios del hijo ${ }^{(4)}$ y dentro de estos factores familiares en diversos estudios se ha estudiado la percepción materna sobre el estado nutricional de su hijo y la importancia que tiene la percepción sobre el peso del hijo, ya que se ha encontrado que madres de niños con SP-OB que no perciben de forma adecuada el peso real del hijo, tienden a subestimarlo y puede generar problemas graves en la salud física y mental del hijo ${ }^{(5-11)}$.

Un inicio para la prevención del SP-OB desde la infancia, es que las madres logren identificar el SP-OB en sus hijos ${ }^{(5,10)}$, como las madres son una gran influencia e intervienen en los comportamientos de salud de los hijos, tales como la actividad física, el desayuno, beber bebidas azucaradas y ver la televisión, entre otras y por promover o restringir estos comportamientos, los padres tienen un papel importante en la prevención y tratamiento del $\mathrm{SP}-\mathrm{OB}$ en los hijos, por lo cual las madres en especial tienen ese papel de suma importancia ya que transmiten las pautas alimenticias al hijo ${ }^{(12,13)}$.

Principalmente todo esto cuando el hijo aún está en la etapa infantil, ya que de acuerdo a Paredes ${ }^{(14)}$ en la etapa infantil principalmente es donde se pueden lograr cambios en los estilos de vida, porque si desde niño se llega a una etapa mayor como la adolescencia y juventud con problemas de SP-OB es muy probable que continúe así durante toda su vida.

Por lo cual es relevante el ayudar a las madres de hijos escolares a que exista una concordancia entre su percepción del peso y el peso real del hijo, ya que en primer lugar, el éxito en una primera intervención como primer paso para cambiar, depende de que se logre tener esa percepción de manera realista del peso del hijo y que se cuente con intervenciones diseñadas para intervenir en poblaciones difíciles con alta prevalencia de obesidad, que es donde la intervención es más urgente ${ }^{(10,15-17)}$.

Con base a lo señalado anteriormente es importante para la disciplina de enfermería la realización del presente estudio ya que servirá de guía para la realización de futuras investigaciones sobre el tema tratado y estas a su vez para diseño de futuras investigaciones con intervenciones con el fin de lograr una percepción materna realista.

Para esta investigación tenemos primeramente la definición de los siguientes términos: "percepción materna del peso del hijo" es el juicio subjetivo referido que la madre hace acerca del peso del hijo en etapa escolar, la cual es medible mediante palabras e imágenes.

Se considera una "percepción adecuada" cuando las madres mencionan por palabras el estado nutricio del hijo así también que seleccionen de manera correcta la silueta correspondiente al estado nutricio del hijo. La "percepción inadecuada" se considera como sobreestimación cuando los datos subjetivos (percepción por imágenes y por palabras) referidos por la madre fueron mayores a los datos objetivos (Índice de Masa Corporal) normales de su hijo y subestimación cuando los datos subjetivos referidos por la madre fueron menores a los datos objetivos normales de su hijo. El "Estado Nutricio" del hijo es la representación mediante el Índice de Masa Corporal (IMC) el cual se clasifico como a) bajo peso, b) peso normal, c) sobrepeso y d) obesidad establecido en las Cartillas Nacionales de Salud en México (Niñas y Niños de 0 a 9 años, Adolescente de 10 a 19 años) tomando en cuenta los criterios establecidos para el rango de edad escolar (6 a 12 años).

Por lo anteriormente plasmado, nuestro objetivo es: Clasificar la percepción materna del peso de su hijo(a) por palabras e imágenes en adecuada o inadecuada y esta última (inadecuada) identificar la subestimación y sobreestimación.

\section{METODOLOGÍA}

\section{Diseño del estudio}

El diseño del estudio es descriptivo-transversal, debido a que únicamente se pretende observar, describir, documentar y comparar aspectos de una situación en particu- 
lar que ocurre de manera natural ${ }^{(18)}$.

Población, muestreo y muestra

La población se conformó por un total de 32 diadas madre-hijo, se seleccionaron los niños de entre 6 y 12 años de una Escuela Primaria Pública ubicada al norte de la ciudad de Sabinas Hidalgo, Nuevo León, México. A partir de un muestreo aleatorio simple, la muestra se calculó utilizando Microsoft Excel 2016 para Windows 10, recurriendo a la fórmula de poblaciones finitas estableciendo un nivel de confianza del $95 \%$ precisión del $2 \%$ y una proporción del $5 \%$, considerando una potencia del .90 para una muestra total de 30 díadas madre-hijo.

\section{Criterios de inclusión}

1.- Niños de edades entre 6 y 12 años.

2.- Capacidad física para mantenerse de pie en mediciones antropométricas.

3.- Voluntariamente y por escrito acepten participar en el estudio.

\section{Instrumentos de medición}

Se utilizó el Cuestionario de Percepciones sobre la Apariencia Física y Salud (CPAFS) ${ }^{(5)}$ mediante el cual se obtiene información sobre las percepciones y preocupaciones que tienen los padres y/o cuidadores de niños con edades entre 2 y 17 años, el cual consta de 19 reactivos, dividido en 6 secciones; para este estudio quedo integrado solamente 5 reactivos para dar respuesta a la percepción por palabras; en la primera sección abarca cuestionamientos acerca de la influencia que se tiene la madre en algunas actividades así como la preocupación por el peso del hijo, tienen respuestas de tipo Likert que van desde "estoy totalmente de acuerdo" a "estoy totalmente en desacuerdo" con cinco diferentes respuestas. En la última sección consta de un panel de 28 imágenes de complexiones físicas dividida en dos secciones de 14 figuras en relación al sexo, así mismo cada sección de acuerdo al sexo se subdivide en dos secciones en relación al rango de edad (6 a 9 años y 9 a 13 años).

Dicho instrumento para evaluar la percepción materna ha sido validado en población mexicana, así también tenemos que la evaluación por palabras cuenta con una sensibilidad de $36 \%$ y especificidad de $84 \%$ y por imágenes una sensibilidad de $70 \%$ y especificidad de $79 \%(19,20)$. Además cuenta con una consistencia interna aceptable (Alfa de Cronbach 0,70).

Para la evaluación del estado nutricional, se midieron las medidas antropométricas (peso y talla) donde posteriormente se obtuvo el IMC y clasificó de acuerdo a lo establecido en las Cartillas Nacionales de Salud en México (de Niñas y Niños de 0 a 9 años, del Adolescente de 10 a
19 años) abarcando la edad estudiada en los niños, basadas en los criterios establecidos por la OMS.

Para obtener la sobreestimación se evalúan los datos subjetivos (percepción por imágenes y por palabras) referidos por la madre fueron mayores a los datos objetivos (Índice de Masa Corporal) normales de su hijo y se obtendrá la subestimación mediante la evaluación de los datos subjetivos referidos por la madre y estos fueron menores a los datos objetivos normales de su hijo.

\section{Procedimiento para obtención de datos}

Se realizaron los debidos trámites administrativos para el acceso a la institución educativa, donde se solicitaron como datos oficiales los listados de los alumnos inscritos en el periodo escolar proporcionados a través de las autoridades de la institución educativa ubicada en Sabinas Hidalgo, Nuevo León, se calculó la selección aleatoria considerando los datos anteriormente mencionados y se obtuvieron las tablas de números aleatorios. Posteriormente, se llevó a cabo una notificación a las madres de los niños seleccionados por parte de la directora de la escuela primaria, que asistieran éstas con fecha programada, previamente al comienzo de la aplicación del instrumento, se explicó el formato que tiene por título consentimiento informado a todas las madres que estuvieron presentes; después se obtuvo el asentimiento de los niños y consentimiento informado firmado por las madres o tutor legal, dicho documento incluye el permiso para obtener información personal así como medir y pesar a sus hijos.

Posteriormente, se les explicó de manera clara y precisa sobre la forma en que tuvieron que llenar el instrumento, con la finalidad que fuera comprensible y que las respuestas fueran las correctas para lograr los objetivos de la investigación. Se llevó un tiempo de 5 a 10 minutos como máximo por cada madre para contestar el cuestionario. En un área especial proporcionada por la dirección de la escuela primaria se procedió a la toma de medidas antropométricas de los niños por los responsables de la investigación.

El peso se obtuvo con una báscula marca SECA con capacidad máxima de 200 kilogramos con una diferencia de 0.1 kilogramos, autocalibrada, la ropa de los niños fue lo más ligera posible y se les pidió quitarse el calzado antes de subir a la báscula. La talla fue obtenida con un estadimetro de pared marca SECA con límite máximo de 2.10 metros, los niños sin zapatos y con los pies juntos de los talones, sin inclinar la cabeza hacia arriba o hacia abajo. Durante este procedimiento se tomaron medidas de seguridad como evitar el piso mojado, colocar tapete antiderrapante, mantener un orden entre los niños, esto con el fin de evitar alguna caída o golpe, todo esto por el mínimo riesgo que conlleva la toma de peso y talla de los niños. 
Tabla 1. Influencia de las madres en actividades y preocupación por el peso del hijo

\begin{tabular}{|c|c|c|c|c|c|c|c|c|c|c|c|}
\hline & \multicolumn{2}{|c|}{ TA } & \multicolumn{2}{|c|}{ EA } & \multicolumn{2}{|c|}{$\mathrm{N}$} & \multicolumn{2}{|c|}{ EA } & \multicolumn{2}{|c|}{ TD } & \multirow[b]{2}{*}{ Total } \\
\hline & $f$ & $\%$ & $f$ & $\%$ & $f$ & $\%$ & $f$ & $\%$ & $f$ & $\%$ & \\
\hline $\begin{array}{l}\text { 1. Puedo influir en lo } \\
\text { que mi niño(a) selec- } \\
\text { ciona para comer }\end{array}$ & 7 & 23.3 & 10 & 33.3 & 10 & 33.3 & 2 & 6.7 & 1 & 3.3 & 30 \\
\hline $\begin{array}{l}\text { 2. Puedo influir en la } \\
\text { cantidad de actividad } \\
\text { física que hace mi hi- } \\
\text { jo(a) }\end{array}$ & 7 & 23.3 & 11 & 36.7 & 9 & 30.0 & 1 & 3.3 & 2 & 6.7 & 30 \\
\hline $\begin{array}{l}\text { 3. Es muy probable que } \\
\text { los niños(as) con SP } \\
\text { tengan SP-OB cuando } \\
\text { son adultos }\end{array}$ & 11 & 36.7 & 11 & 36.7 & 3 & 10.0 & 4 & 13.3 & 1 & 3.3 & 30 \\
\hline $\begin{array}{l}\text { 4. Es más probable que } \\
\text { los niños(as) con SP se } \\
\text { les desarrollen DM que } \\
\text { a niños que no tienen } \\
\text { SP. }\end{array}$ & 14 & 46.7 & 12 & 40.0 & 1 & 3.3 & 2 & 6.7 & 1 & 3.3 & 30 \\
\hline $\begin{array}{l}\text { 5. Las costumbres de } \\
\text { alimentación de los } \\
\text { padres influencian las } \\
\text { costumbres de alimen- } \\
\text { tación de los niños(as). }\end{array}$ & 13 & 43.3 & 8 & 26.7 & 6 & 20.0 & 2 & 6.7 & 1 & 3.3 & 30 \\
\hline Fuente: CPAFS & & & & & & & & & & & $\boldsymbol{n}=30$ \\
\hline
\end{tabular}

Se ocupó un tiempo aproximado de 5 minutos como máximo por cada niño al momento de pesarlo y medirlo. Al término se agradeció a las madres y sus hijos(as) por su participación en el trabajo de investigación, así como al director y maestros de la institución educativa por las facilidades otorgadas ante la realización de la investigación.

\section{Análisis estadístico}

Los datos se capturaron y analizaron en el paquete estadístico Statistical Package for the Social Sciences (SPSS) versión 22 para Windows 8.1. Se obtuvieron estadísticas descriptivas y se recurrió al empleo de la media, desviación estándar así como el uso de frecuencias y porcentajes, lo anterior para dar respuesta a los objetivos de investigación.

\section{Consideraciones éticas}

El presente estudio fue aprobado por el comité de ética de la institución educativa y se apegó a las disposiciones dictadas en el Reglamento de la Ley General de Salud en Materia de Investigación de la Secretaría de Salud, haciendo énfasis que fue una investigación con riesgo mínimo (Articulo 17) y se hizo uso de consentimiento y asentimiento informado por tratarse de menores de edad (Articulo 36) (21).

\section{RESULTADOS}

Participaron 30 diadas madre-hijo. La edad promedio de las madres fue de 33.77 años $(D E=8.003)$, la mayoría de las madres (40\%) tienen una escolaridad hasta secundaria, solteras (50\%) y se dedican al hogar (76.7\%), se reportó un promedio de ingreso económico familiar mensual de $\$ 3,500 \mathrm{M} / \mathrm{N}$ (US $\$ 207.22$ ) ( $D E=1050.451$ ). Respecto a los hijos, la edad promedio del hijo fue de 8.67 años $(D E=1.971)$, se reportó un $56.7 \%(n=17)$ de 
hijos de sexo masculino y un $43.3 \%(n=13)$ de sexo femenino.

Respecto al Estado Nutricio (EN) obtenido mediante el IMC de acuerdo a lo establecido en la Cartilla Nacional de Salud en México, se identificó un $80 \%$ para peso normal $(n=24)$ y un $20 \%$ para SP-OB $(n=6)$.

Al analizar las preguntas sobre influencia que tienen las madres en actividades y preocupación por el peso del hijo, se sumaron los resultados obtenidos de TA y EA como respuestas mayormente positivas a los cuestionamientos acerca de la influencia que tiene la madre en algunas actividades (preguntas 1 y 2) así como la preocupación por el peso del hijo (preguntas 3, 4 y 5), se logró identificar que la mayoría de las madres estuvieron de acuerdo en que pueden influir en la selección de lo que comen y la realización de actividad física de sus hijos así como al alto porcentaje que a las madres les preocupa el peso y salud de su hijo así como la influencia de las costumbres de alimentación hacia los hijos (tabla 1).

Al analizar la Percepción Materna por Palabras (PMP) del peso de hijo de acuerdo al Estado Nutricio (EN) y su sexo (tabla 2). Se identificó una mayor Percepción Adecuada (PA) en niñas y niños con $61.6 \%(n=8)$ y $52.9 \%$ $(n=9)$ respectivamente. En general, de acuerdo al EN de hijos con peso normal se encontró una mayor PA (70.9\%) ( $n=17)$, en cambio en los hijos con SP-OB hubo un 100\% $(n=6)$ de PI. Generalizando los datos hubo mayor PA $(56.7 \%)(n=17)$ que PI $(43.3 \%)(n=13)$.

Al analizar la Percepción Materna por Imágenes (PMI) del peso de hijo (tabla 3), se identificó en la PMI de las niñas un $53.9 \%(n=7)$, en los niños se encontró una mayor PA con $58.9 \%(n=0)$. Generalizando los datos obtenidos hubo mayor PA (53.3\%) $(n=16)$ que PI $(46.7 \%)$ $(n=14)$.

De acuerdo a la tabla 4, al analizar la comparación de las evaluaciones de PMP y PMI en ambas evaluaciones se obtuvo mayor PA $56.7 \%(n=17)$ y $53.3 \%(n=6)$ respectivamente.

Al analizar la subestimación y sobreestimación de la Percepción Inadecuada en la PMI (tabla 5), se encontró en la PI de Niñas una mayor subestimación (85.7\%) $(n=6)$. Respecto a la PI de Niños se encontró una mayor subestimación $71.4 \%(n=5)$. Generalizando los datos obtenidos se encontró una mayor subestimación con $78.6 \%(n=11)$.

Posteriormente al analizar si en la PMP la PI $(n=13)$ se presentó subestimación o sobreestimación de acuerdo al estado nutricio y sexo del hijo, se encontró en la PI de niñas con peso normal y obesidad un $100 \%(n=5)$ de subestimación. Respecto a la PI de niños con peso normal, SP y OB se identificó un 100\% $(n=8)$ de subestimación. Generalizando los datos obtenidos se encontró un 100\% $(n=13)$ de Subestimación.

\section{DISCUSIÓN}

Se tiene conocimiento que la percepción es el proceso de organizar e interpretar información sensorial para darle un significado, la percepción de personas es una de las áreas que constituye la percepción social que se dedica a investigar los procesos y mecanismos por los cuales la personas elaboran y generan la información sobre los otros y sobre sí mismos ${ }^{(22)}$ en este caso tratando respecto a la Percepción Materna, la cual mediante la literatura revisada se refiere a la interpretación que tiene la madre respecto al estado nutricio de su hijo y son ubicados de un parámetro de estado nutricional en una imagen corporal que es el concepto que la persona tiene del cuerpo, propio u otro, percepción que puede ser igual, parecida o decididamente diferente a la imagen que la persona proyectase ${ }^{(23)}$.

Los resultados del presente estudio permitieron identificar dentro de la percepción materna del peso del hijo escolar una diferencia mínima entre la PMI y PMP obteniendo una diferencia no significativa. Respecto a los hallazgos como respuesta para el primer objetivo, en general para ambos métodos utilizados al analizar la PMI-PMP hay mayor percepción adecuada en ambos, resultados similares a otros estudios realizados en los cuales se encontró una mayor percepción adecuada ${ }^{24,27)}$. Nuestros resultados son diferentes ya que encontramos porcentajes mayores de concordancia en niños con peso normal y SP-OB en comparación con otro estudio ${ }^{(25)}$. Al igual que porcentajes muy por debajo de lo encontrado en otro estudio respecto a la PMP, pero resultados similares de percepción adecuada en la PMI (26).

En un estudio realizado por Zonana-Nacach y Conde-Gaxiola (27) se encontró que más de la mitad de las madres percibió el peso de su hijo correctamente, en un estudio de Guevara-Cruz ${ }^{(28)}$ se encontró una percepción adecuada en más de la mitad de las madres, de igual manera en el presente estudio se encontró una percepción adecuada en más de la mitad de las madres para PMI y para PMP, en la cual puede dar variaciones de resultados dado que el estado nutricional de los niños/as tuvieron pequeñas variaciones.

Es importante mencionar que las imágenes diseñadas en el estudio de Eckstein et al. ${ }^{(5)}$ que contienen una serie de 7 imágenes de complexiones corporales en 4 rangos distintos de edades que van de 2 hasta 17 años da a las madres mayor posibilidad de poder identificar el SP-OB en hijos dado que ofrece 4 opciones para poder identificarlo.

Continuando con la respuesta al objetivo principal, se encuentra que en los casos de PI en la PMI encontramos un alto porcentaje de subestimación, igual en la PI de PMP. 
Tabla 2. Percepción Materna por Palabras de acuerdo al estado nutricio y sexo del hijo

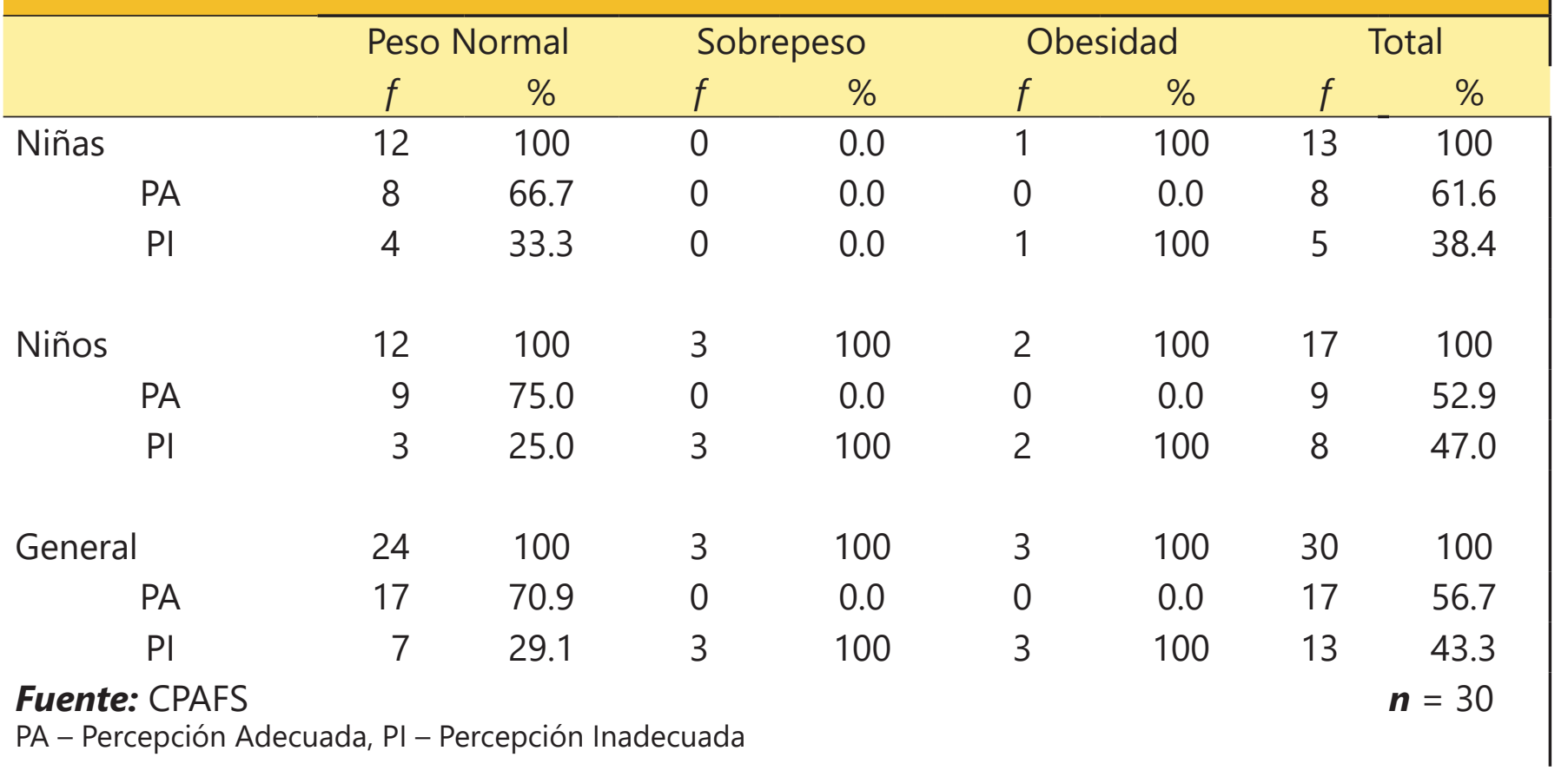

Principalmente las madres para ambas percepciones subjetivas (imágenes y palabras) subestiman el estado nutricio de sus hijos en poco porcentaje para peso normal con un mayor porcentaje en comparación con las demás clasificaciones del peso, tales hallazgos fueron superiores en comparación con otro estudio ${ }^{(25)}$. En relación a la subestimación y sobreestimación de la PI, se identificó un alto porcentaje de subestimación, en si las madres que perciben inadecuadamente el peso de su hijo lo subestima, esto quiere decir que valora el estado nutricio por debajo del valor que presenta realmente.

Respecto a esto contamos con porcentajes muy por encima en comparación con otro estudio en el cual solo se presentó $37 \%$ de subestimación ${ }^{(27)}$. Al igual que estos resultados son algunos estudios donde se observa una subestimación del peso del hijo por parte de las madres $(17,29)$

Cabe mencionar que las madres logran influir en la alimentación y actividad física del hijo, así como les preocupa el peso y salud del hijo, aunque no logran tener una percepción adecuada y subestiman/sobreestiman el estado nutricio en el cual realmente se encuentra el hijo, lo cual puede llegar a interferir en las actividades que realice la madre en la salud del hijo.

Es importante el promover una correcta percepción por parte de la madre, que se reconozca el tamaño del cuerpo, apariencia física, capacidades funcionales, efectos psicosociales y efectos sobre la salud relacionados con el peso corporal, por consecuente se promueve una preocupación por parte de la madre, un mayor reconocimiento sobre los riesgos de salud que se pueden presentar debido a un alto peso corporal, la motivación para hacer cambios de estilos de vida y cambios en la familia, con el objetivo final de presentar un peso saludable para el niño, así también el identificar los factores que se asocian a esta percepción de la madre para lograr realizar modificaciones mediante intervenciones específicas para el apoyo a una mejor percepción de la madre hacia el peso de los hijos ${ }^{(30,31)}$.

\section{Recomendaciones}

Realizar estudios con mayor muestra que permitan generalizar resultados, especialmente en las comunidades rurales debido a que es donde se encuentra un mayor porcentaje de la prevalencia combinada de SP-OB, así también que abarque el análisis de los factores causales de la distorsión de la percepción materna sobre el peso del hijo, esto con el fin de diseñar intervenciones hacia una mejor percepción de peso del hijo.

Diseñar, implementar y evaluar intervenciones tanto propias de enfermería como multidisciplinarias para la prevención del sobrepeso-obesidad mediante la correcta percepción materna del peso y promoción de estilos de vida saludables en la infancia, para esto, tomar en cuenta los diversos factores socioculturales presentes en la población a fin de dar un cumplimiento exitoso. 
Tabla 3. Percepción Materna por Imágenes de acuerdo al estado nutricio y sexo del hijo

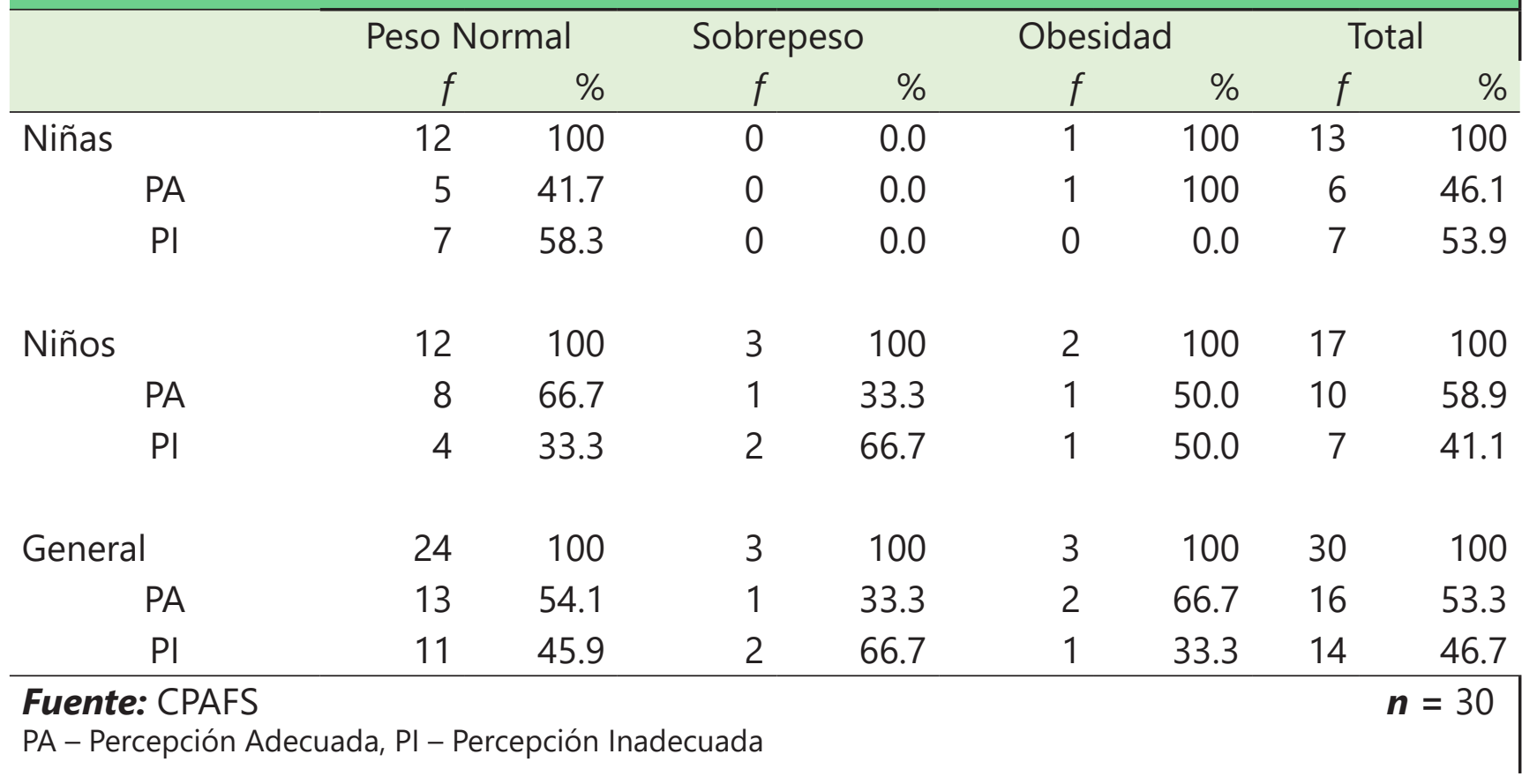

Tabla 4. Comparación de Percepción Materna por Palabras/ por Imágenes de acuerdo al Estado Nutricio

\begin{tabular}{lrrrrrrrrr}
\hline & & \multicolumn{1}{c}{ Normal } & \multicolumn{2}{c}{ Sobrepeso } & \multicolumn{2}{c}{ Obesidad } & \multicolumn{2}{c}{ Total } \\
& & $f$ & $\%$ & $f$ & $\%$ & $f$ & $\%$ & $f$ & $\%$ \\
\hline PMP & Total & 24 & 100 & 03 & 0.0 & 03 & 0.0 & 30 & 100 \\
& PA & 17 & 70.8 & 0 & 0.0 & 0 & 0.0 & 17 & 56.7 \\
& P1 & 07 & 29.2 & 03 & 100 & 03 & 100 & 13 & 43.3 \\
& & & & & & & & & \\
PMI & Total & 24 & 100 & 03 & 100 & 03 & 100 & 30 & 100 \\
& PA & 13 & 50.0 & 01 & 100 & 02 & 100 & 16 & 53.7 \\
& Fuente: CPAFS & 11 & 50.0 & 02 & 0.0 & 01 & 0.0 & 14 & 46.7 \\
& & & & & & & & $n$ & $\boldsymbol{n}=30$
\end{tabular}

PA - Percepción Adecuada, PI - Percepción Inadecuada

PMP - Percepción Materna por Palabras, PMI - Percepción Materna por Imágenes

Realizar investigaciones donde se ejecuten intervenciones propias de enfermería, dirigidas no solo a las madres, sino a todo el núcleo familiar el cual influye en las actividades nutricionales del niño. Así como el estudio de otras herramientas para concientizar a las madres que sus hijos presentan un problema de peso.

\section{Limitaciones}

La muestra estudiada es menor, por lo cual no permite generalizar resultados.

\section{CONCLUSIONES}

Las madres de hijos escolares tienen una percepción mayormente adecuada. Existe mayor Percepción Adecuada en hijos varones en la Percepción Materna por Imágenes, caso contrario en la Percepción Materna por Palabras. De los casos que se presentaron como Percepción Inadecuada para ambos sexos, existe un alto porcentaje de subestimación. 


\begin{tabular}{cccccccccc}
\multicolumn{2}{l}{ Tabla 5. Subestimación y Sobreestimación en la Percepción Materna por Imágenes } \\
\hline & \multicolumn{3}{c}{ Normal } & \multicolumn{2}{c}{ Sobrepeso } & \multicolumn{2}{c}{ Obesidad } & \multicolumn{2}{c}{ Total } \\
& $f$ & $\%$ & $f$ & $\%$ & $f$ & $\%$ & $f$ & $\%$ \\
\hline $\mathrm{PI}-$ Niñas & 7 & 100 & 0 & 0.0 & 0 & 0.0 & 7 & 100 \\
Subestimación & 6 & 85.7 & 0 & 0.0 & 0 & 0.0 & 6 & 85.7 \\
Sobreestimación & 1 & 14.3 & 0 & 0.0 & 0 & 0.0 & 1 & 14.3 \\
& & & & & & & & \\
$\mathrm{PI}-$ Niños & 4 & 100 & 2 & 100 & 1 & 100 & 7 & 100 \\
Subestimación & 2 & 50.0 & 2 & 100 & 1 & 100 & 5 & 71.4 \\
Sobreestimación & 2 & 50.0 & 0 & 0.0 & 0 & 0.0 & 2 & 28.6 \\
& & & & & & & & \\
General & 11 & 100 & 2 & 100 & 1 & 100 & 14 & 100 \\
Subestimación & 8 & 72.7 & 2 & 100 & 1 & 100 & 11 & 78.6 \\
Sobreestimación & 3 & 27.3 & 0 & 0.0 & 0 & 0.0 & 3 & 21.4 \\
\hline
\end{tabular}

\section{Fuente: CPAFS}

$\boldsymbol{n}=14$

$\mathrm{PI}$ - Percepción Inadecuada

\section{REFERENCIAS BIBLIOGRÁFICAS}

1. Organización Mundial de la Salud (OMS). Obesidad y sobrepeso. Ginebra: OMS; 2015.

2. Organización Mundial de la Salud (OMS). Sobrepeso y obesidad infantiles. Ginebra: OMS; 2016.

3. Instituto Nacional de Salud Pública. Encuesta Nacional de Salud y Nutrición 2012. Resultados por entidad federativa, Nuevo León. Cuernavaca, México: Instituto Nacional de Salud Pública.; 2013.

4. Ortiz-Félix RE, Flores-Peña Y, Cárdenas-Villarreal VM, Moral de la Rubia J, Ruvalcaba Rodríguez MD, Hernández-Carranco RG. Predictores maternos del índice de masa corporal del hijo pre-escolar y escolar. ALAN. 2015;65(3):158-165.

5. Eckstein K, Mikhail L, Ariza A, Thomson S, Millard S, Binns H. Parent's perceptions of their child's weight and health. Pediatrics. 2006;117(3):681-690.

6. Bracho MF, Ramos HE. Percepción materna del estado nutricional de sus hijos: ¿Es un factor de riesgo para presentar malnutrición por exceso? Rev Chil Pediatr. 2007;78(1):20-27.

7. Flores-Peña Y, Cárdenas-Villarreal VM, Trejo-Ortiz PM, Ávila-Alpirez H, Ugarte-Esquivel A, Gallegos-Martínez J. Maternal actions and problems in managing the child's weight and their association with the maternal perception of the weight and age of her child. Nutr Hosp. 2014;29(4):822-828.

8. Giordano SA, Sartori ML. Percepción de las madres del estado nutricional de sus niños en una escuela primaria de Cachi (Salta, Argentina). CIMEL. 2012;17(1):37-41. 9. Flores-Peña Y, Acuña-Blanco A, Cárdenas-Villarreal VM, Amaro-Hinojosa MD, Pérez-Campa ME, Elenes-
Rodríguez JR. Asociación de la percepción materna del peso del hijo y estilos maternos de alimentación infantil. Nutrición Hospitalaria. 2017;34(1):51-58.

10. Zamudio-Solorio O, Muñoz-Arenillas RM. Percepción de los padres respecto al sobrepeso y obesidad de sus hijos. Rev Enferm Inst Mex Seguro Soc. 2016;24(1):61-64. 11. Furlong $M$, Glejzer $M$, Wechsler $C$, Rossetti $A$, Zappone MC, Fortunato $C$. Motivación y adherencia al tratamiento de niños de 6 a 13 años con sobrepeso y obesidad del HIGA Eva Perón. Inmanencia.

2015;4(2):113-117.

12. Remmers $T$, Grieken AV, Renders $C M$, Hirasing

RA, Broeren SML, Raat H. Correlates of Parental Misperception of Their Child's Weight Status: The Be Active, Eat Right Study. Plose One. 2004;9(2):e88931. 13. Domínguez-Vázquez P, Olivares S, Santos JL. Influencia familiar sobre la conducta alimentaria y su relación con la obesidad infantil. Archivos Latinoamericanos de Nutrición. 2008;58(3):249-255. 14. Paredes Sierra R. Sobrepeso y obesidad en niños y adolescentes [Internet]. [Acceso 19 de Enero de 2016]. http://www.facmed.unam.mx/sms/seam2k1/2007/ ago_01_ponencia.html

15. Pakpour AH, Yekaninejad MS, Chen H. Mothers' perception of obesity in schoolchildren: a survey and the impact of an educational intervention. Journal Pediatric. 2011;87(2):169-174.

16. Rietmeijer-Mentink M, Paulis MD, van Middelkoop M, Bindels PJ, van der Wouden JC. Difference between parental perception and actual weight status of children: a systematic review. Matern Child Nutr. 2013:9(1):3-22. 17. Polit DF, Hungler BP. Investigación científica en ciencias de la salud. México: McGraw-Hill- 
Interamericana: 2014

18. Flores-Peña Y, Trejo-Ortiz, PM, Gallegos-Cabriales EC, Cerda-Flores RM. Validez de dos pruebas para evaluar la percepción materna del peso del hijo. Salud Pública de México. 2009;51(6):489-495

19. Ávila Alpirez H, Gutiérrez Sánchez G, Martínez Aguilar ML, Vázquez Galindo L. Determinar la sensibilidad y especificidad de la Percepción Materna del Peso de su descendiente de la frontera norte de Tamaulipas por palabras/ por imágenes frente al estándar de oro. Cultura de los Cuidados. 2017;21(47):185-193.

20. Secretaria de Salud. Reglamento de la Ley General de Salud en Materia de Investigación para la Salud [Internet]. México D.F.: SSA; 1987 [Acceso febrero 2015]. http://www.diputados.gob.mx/LeyesBiblio/regley/Reg_ LGS_MIS_orig_06ene87.pdf

21. Gómez L, Canto JM. Psicología Social. Madrid, España: Ediciones Pirámide; 2000.

22. Salazar JM, Montero M, Muñoz C, Sánchez E, Santero E, Villegas J. Percepción social. En Asociación Venezolana de Psicología (Eds.). Psicología social. México: Trillas; 2003.

23. Cabrera N, Rolón R, Mañotti LG, Sanabria MC, Arredondo M, Pizarro F. Concordancia entre la percepción materna y el estado nutricional real de niños preescolares que asisten a la consulta de pediatría general. Pediatr. 2013;40(3):235-240.

24. Lara-García B, Flores-Peña Y, Alatorre-Esquivel MA, Sosa-Briones R, Cerda-Flores RM. Percepción materna de sobrepeso-obesidad infantil y riesgos de salud en Nuevo Laredo, Tamaulipas, México. Salud Pública de México. 2011;53(3):258-263.

25. Flores-Peña Y, Camal-Ríos NY, Cerda-Flores RM. Evaluación de la percepción materna del peso del hijo y de la heredabilidad del IMC en diadas mestizas del Sureste de México. ALAN. 2011;61(4):389-395.

26. Zonana-Nacach A, Conde-Gaxiola ME. Percepción de las madres sobre la obesidad de sus hijos, Gac Méd Méx. 2010;146(3):165-168.

27. Guevara-Cruz M, Serralde-Zúñiga AE, VázquezVela MEF, Blancas-Galicia L, Islas-Ortega L. Association between maternal perceptions and actual nutritional status for children in a study group in Mexico. Nutrición Hospitalaria. 2012;27(1):209-212.

28. Binkin N, Spinelli A, Baglio G, Lamberti A. What is common becomes normal: the effect of obesity prevalence on maternal perception. Nutr Metab Cardiovasc Dis. 2013;23(5):410-416.

29. Angarita A, Martínez A, Rangel C, Betancourt MV, Prada GE. Determinantes de la subestimación de la percepción de los padres sobre el peso de sus hijos en hogares infantiles del ICBF de Floridablanca, Colombia, 2012. Rev Chil Nutr. 2014;41(4):372-382.

30. Mareno N. Parental perception of child weight: a concept analysis. J Adv Nurs. 2014;70(1):34-45.
31. Trejo-Ortíz P, Ahumada-Saucedo J. Factores asociados a la percepción materna del peso corporal del hijo: una revisión sistemática. Santiago. 2016; 222-233. 